\title{
Influence of territorial variables on the performance of wildfire detection systems in the Iberian Peninsula ${ }^{2}$
}

\author{
Francisco Rego ${ }^{\text {a,* }}$, Filipe X. Catry ${ }^{\text {a }}$, Cristina Montiel ${ }^{\text {b }}$, Oskar Karlsson ${ }^{\text {b }}$ \\ a Centre for Applied Ecology, School of Agriculture, Technical University of Lisbon, Tapada da Ajuda, 1349-017 Lisbon, Portugal \\ b Department of Regional Geography and Physical Geography, Faculty of Geography and History, University Complutense of Madrid, Profesor Aranguren s/n, 28040 Madrid, Spain
}

\section{A R T I C L E I N F O}

Article history:

Received 7 December 2010

Received in revised form 2 November 2012

Accepted 3 November 2012

\section{Keywords:}

Wildfire detection

Land cover

Lookout towers

Mobile brigades

Portugal

Spain

\begin{abstract}
A B S T R A C T
Wildfire detection systems planning is an essential component of national and regional wildfire management policies. The common resources usually used in wildfire detection are lookout towers, terrestrial mobile brigades, aerial reconnaissance and the general public.

The objectives of this paper are (i) to analyse the relative importance of the different detection systems in Portugal and Spain, according to their spatial and temporal patterns, (ii) to assess the territorial variables related to the performance of fire detection systems in the Iberian Peninsula, and (iii) to develop an explanatory model aiming to inform fire detection policies.

Pursuing this aim, a common wildfire and territorial database for the whole Iberian Peninsula was developed, thus enabling common cartographic and statistical analyses. Results show the importance of land cover variables and population density on the proportion of fire detections made by the different systems in both countries.

Despite certain national specificities, many common features were found, allowing the identification of general patterns of fire detection distribution and performance for the Iberian Peninsula. Models developed at the regional and sub-regional levels indicate that high population density and high proportion of forestlands are associated with higher proportion of detection by population, whereas higher proportion of shrublands corresponds to higher proportions of detections by other systems, particularly lookout towers.

The conclusions obtained and the approaches applied could be used with similar objectives in other countries and regions to inform policy decisions regarding the allocation of resources for wildfire detection.
\end{abstract}

(c) 2012 Elsevier B.V. All rights reserved.

\section{Introduction}

Portugal and Spain are part of the Mediterranean Basin region, where wildfires are the most important natural hazard (European Commission, JRC, 2009). During the period from 2001 to 2007, over 40,000 fires were recorded each year in the Iberian Peninsula. Following the 2003 fire season in Portugal, with 426,000 ha of burned area, the 2005 season was the worst recorded in Spain, with 189,000 ha of burned area. This same year catastrophic fires also ravaged Portugal, representing 338,000 ha of burned area. Then, a wave of fires devastated 87,000 plus hectares in Galicia from the 3rd to 15th of August 2006. As a consequence of these episodes of catastrophic wildfires in the Iberian Peninsula, the necessity to improve the national fire management systems, including the efficiency and optimisation of detection systems, is considered in both countries in order to reduce the average burned area and the number of large wildfires.

\footnotetext{
th This article belongs to the Special Issue: Fire use policies and practices in Europe: Solving the Fire Paradox.

* Corresponding author. Tel.: + 351213616085 ; fax: + 351213623493.

E-mail address: fcastrorego3@gmail.com (F. Rego).
}

Wildfire detection is based on a series of activities and opportunities whose objective is to discover, locate and report a fire ignition to the fire communication centre (Ruiz, 2000). Wildfire detection systems are considered for a long time to be crucial in order to enable the reduction of fire fighting costs and fire losses. Thus, wildfire detection planning is a part of the integrated fire management organization to be adopted by a national or regional fire management agency (Chandler et al., 1983; Catry et al., 2007).

There are different methods and resources used for wildfire detection, depending on the operational fire management organization and they can be classified into different categories for statistical purposes in each country. The wildfire detection systems are usually classified into four main categories: a) the general public (hereafter designated as population), b) lookout towers, c) terrestrial mobile brigades (e.g. forest rangers, National Guard), and d) aerial reconnaissance (performed using aircrafts, hereafter designated as aerial means). Several differences affect their performance and efficiency, such as their public or private nature, their mobility, the technology used, and the terrestrial or aerial mode of operation. Thus, other ways of classifying the detection systems based on different criteria, are also possible: (i) official (i.e. lookout towers, mobile brigades and aerial 
means) versus public (i.e. the general public or population) detection systems; (ii) fixed (lookout towers) versus mobile (ground brigades, aircrafts and population) systems; (iii) terrestrial (lookout towers, mobile brigades and population) versus aerial (aircrafts) systems.

The choice of the appropriate combination of systems for optimal fire management requires the analysis of the factors influencing the performance and efficiency of the different detection systems. Previous research on fire detection systems has focused on several aspects from different methodological approaches, especially in the following topics:

1. Qualitative analysis of advantages and disadvantages of the different detection systems (Chandler et al., 1983; Colaço et al., 2008, 2009; Montiel et al., 2009);

2. The assessment of detection systems' efficiency, has been estimated as a function of (i) the proportion of wildfires detected by each system, and (ii) accuracy of wildfire location (Pérez et al., 2007);

3. GIS analysis of viewsheds from lookout towers (Catry et al., 2007; Rego and Catry, 2006);

4. Contribution of new technologies (infrared and video cameras, remote sensing, laser detection, unmanned aerial vehicles, satellites, etc.) to the operational capacity of the ground detection systems (Arrue et al., 2006; Oliva et al., 2008; Ko et al., 2009; Seric et al., 2009; Zervas et al., 2009).

Thereby, in order to meet current policy demands and to fulfil research gaps, it is necessary to develop comparative assessments of detection systems performance and to evaluate the competition and possible synergies between them, in order to provide decision support criteria for detection systems planning. The assessment of the relation between the detection systems performance and territorial variables such as population density, land cover and elevation is also important. Relations between this type of territorial variables and fire ignition occurrence have been previously reported in southern Europe (Catry et al, 2009; Moreira et al., 2010), and it is expected that they are also related to detection. In fact, the method of detection should be closely correlated with the type of detection problem (Chandler et al., 1983), which is defined by social and spatial parameters (Catry et al, 2010; Romero et al., 2007).

In this context, the objectives of this paper are (i) to analyse the relative importance of the different wildfire detection systems in Portugal and Spain (Fig. 1), according to their spatial and temporal patterns, (ii) to assess the territorial variables related to the performance of fire detection systems in the Iberian Peninsula, and (iii) to develop an explanatory model aiming to inform fire detection policies.

\section{Methods}

\subsection{Study area and spatial levels}

The study area for this study is the entire Iberian Peninsula. This region is located in south-western Europe (western Mediterranean Basin), and includes two countries: Portugal and Spain.

In this paper, data collection and analysis were performed at four spatial levels, within the Iberian Peninsula:

- The national level, i.e. Portugal (PT) and Spain (ES), as the two Iberian countries;

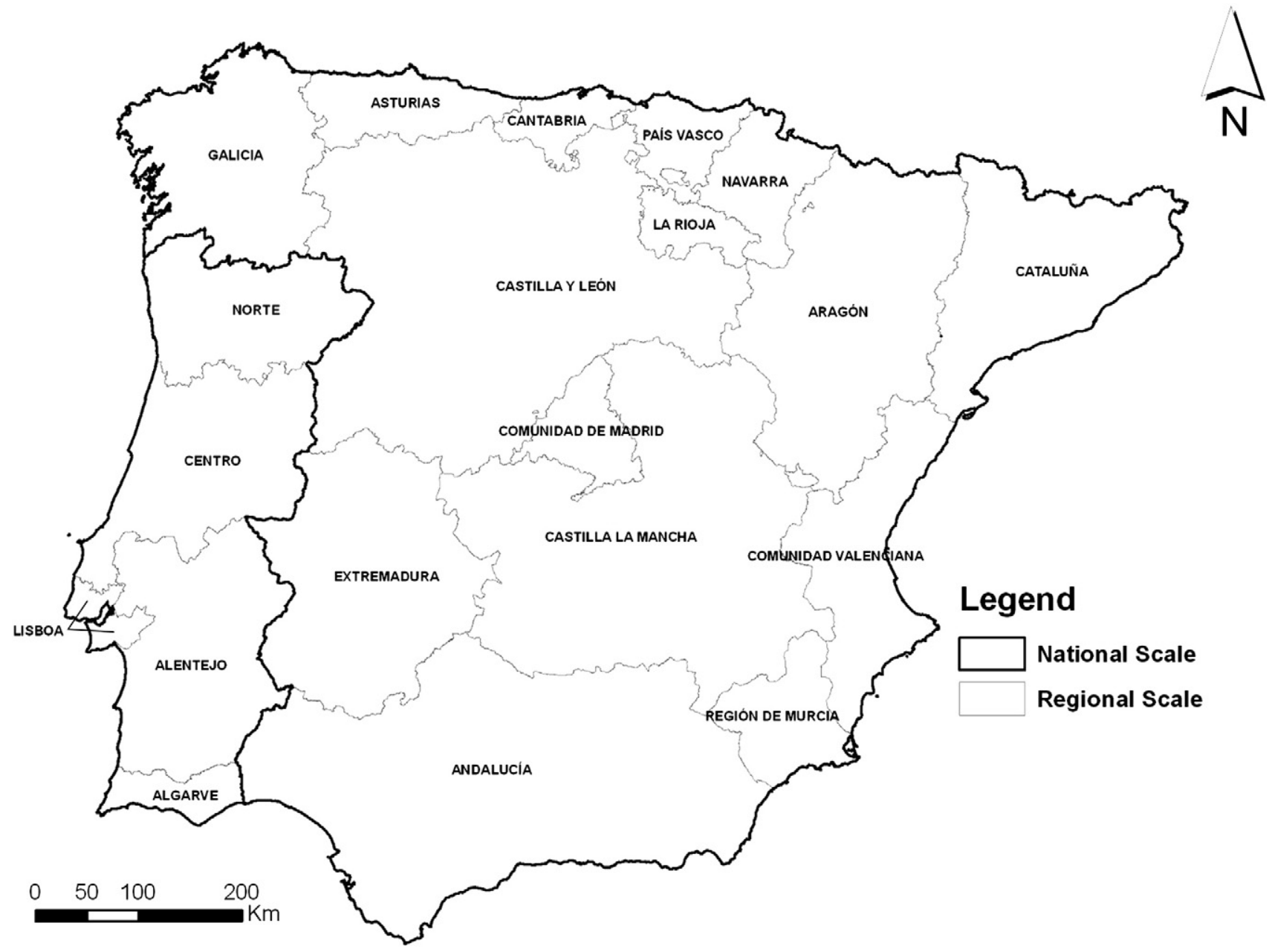

Fig. 1. Iberian Peninsula countries and regions. 
Table 1

Summary of the variables used in the statistical analysis.

\begin{tabular}{|c|c|c|c|c|c|}
\hline Type & Topic & Variable & Code & Units & Level \\
\hline \multirow[t]{8}{*}{ Fire detection systems } & \multirow[t]{4}{*}{ Density of resources (availability) } & Population density & Pop_d & Persons $/ \mathrm{km}^{2}$ & Regional; sub-regional \\
\hline & & Lookout towers density & Look_d & Lookouts $/ \mathrm{km}^{2}$ & Regional \\
\hline & & Mobile brigades density & Brig_d & Brigades $/ \mathrm{km}^{2}$ & Regional \\
\hline & & Aerial means density & Aer_d & Aircrafts $/ \mathrm{km}^{2}$ & Regional \\
\hline & \multirow[t]{4}{*}{ Proportion of fires detected } & Detections by population & Pop_prop & $\%$ & Regional; sub-regional \\
\hline & & Detections by lookouts & Look_prop & $\%$ & Regional; sub-regional \\
\hline & & Detections by brigades & Brig_prop & $\%$ & Regional; sub-regional \\
\hline & & Detections by aircrafts & Aer_prop & $\%$ & Regional; sub-regional \\
\hline \multirow[t]{4}{*}{ Others } & \multirow[t]{2}{*}{ Land cover } & Proportion of forests & For_prop & $\%$ & Regional; sub-regional \\
\hline & & Proportion of shrublands & Shrub_prop & $\%$ & Regional; sub-regional \\
\hline & \multirow[t]{2}{*}{ Fire regime } & Proportion of burned area & BA_prop & Burned ha/ $/ \mathrm{km}^{2}$ & Regional \\
\hline & & Wildfire density & Fires_d & Fires $/ \mathrm{km}^{2}$ & Regional \\
\hline
\end{tabular}

The PCA analysis was performed with all variables available at the regional level, and the multiple regression was performed using sub-regional variables.

- The regional level (NUTS2, Nomenclature of Units for Territorial Statistics), as the main political level for Spain, and also an important level for statistics and fire management in both countries;

- The sub-regional level (districts in Portugal and provinces in Spain), as the representative of management units with available statistical data;

- The local level $\left(10 \times 10 \mathrm{~km}^{2}\right.$ grid $)$.

\subsection{Data collection}

In order to compile the required information for the cartographic and statistical analysis on the performance of fire detection systems in the Iberian Peninsula, a fire database for the Iberian Peninsula was developed, including 290,976 records of wildfires detected in Portugal and Spain during the period 2001-2007. This database was built from the official National Forest Services wildfire databases, and included the geographical location of each fire, the date and time of detection, and the detection source. Concerning fire detection, each country has its own classification system. Thus, an integration of the information contained in both national official databases was needed, allowing the definition of four common detection system classes: i) population (i.e. general public), ii) lookout towers, iii) mobile brigades (e.g. forest rangers, National Guard), and iv) aerial means (aircrafts). Since automatic detection systems are almost inexistent in the Iberian Peninsula (only in much localized areas), they are not considered in this paper (their number and contribution to fire detection is negligible).

On the other hand, a second database with territorial variables was developed at the regional and sub-regional levels. Explanatory variables of social and spatial nature (population density, proportion of forests and shrublands) were included, as well as variables related to fire regime (fire density and burned area). Land cover data was obtained from Corine Land Cover cartography (EEA, 2000), and data concerning fire regime was provided by the National Forest Services. The geographical distribution and density of the fire detection systems, related to fire policies implementation, was also considered in the territorial database at the sub-regional level. Data concerning the distribution and number of the existing detection systems was based on a questionnaire formulated by the Complutense University of Madrid in the frame of the Fire Paradox project (contract no. FP6018505), which was sent to the national and regional forest and fire policy representatives. All the information was integrated in a geographic information system (GIS), in order to perform a spatial analysis. A summary of the variables used in this paper is presented in Table 1.

\subsection{Data analysis}

The methodological approach used in this paper for analysing the relationship between territorial variables and fire detections

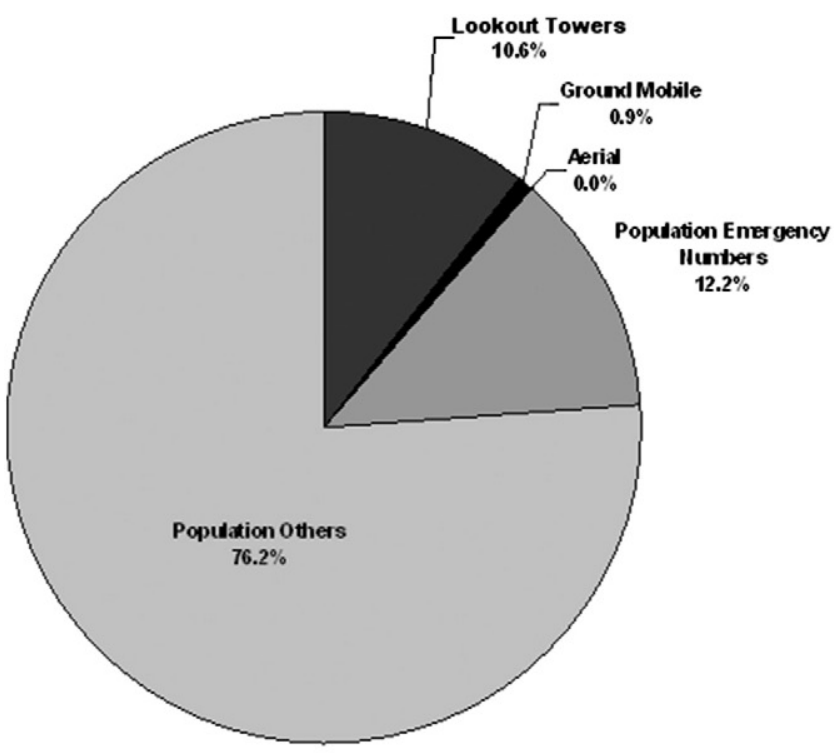

Portugal

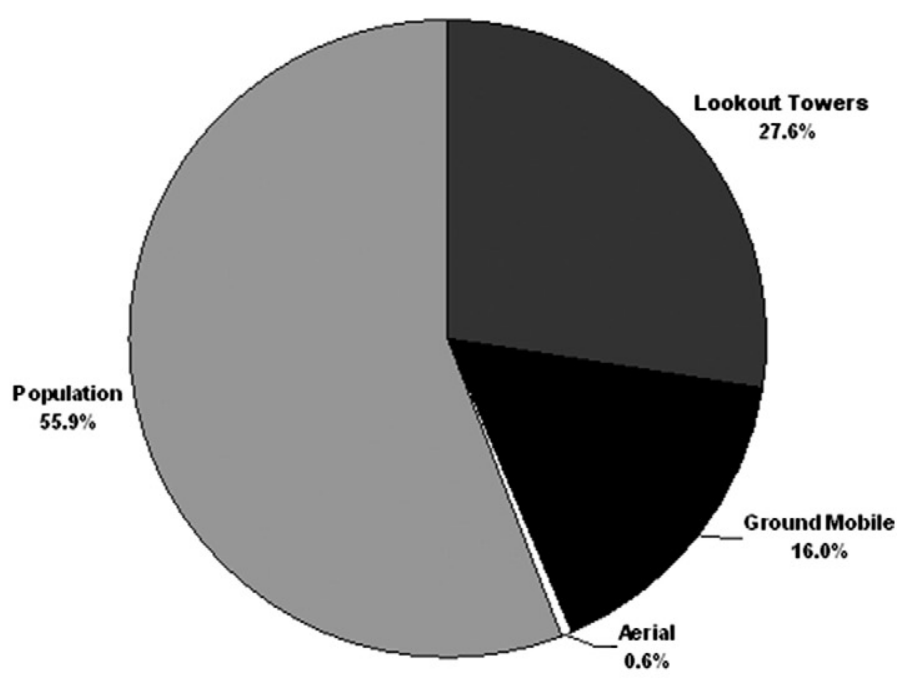

Spain

Fig. 2. Proportion of wildfire detections performed by each detection system in Portugal and Spain, during the period 2001-2007. 

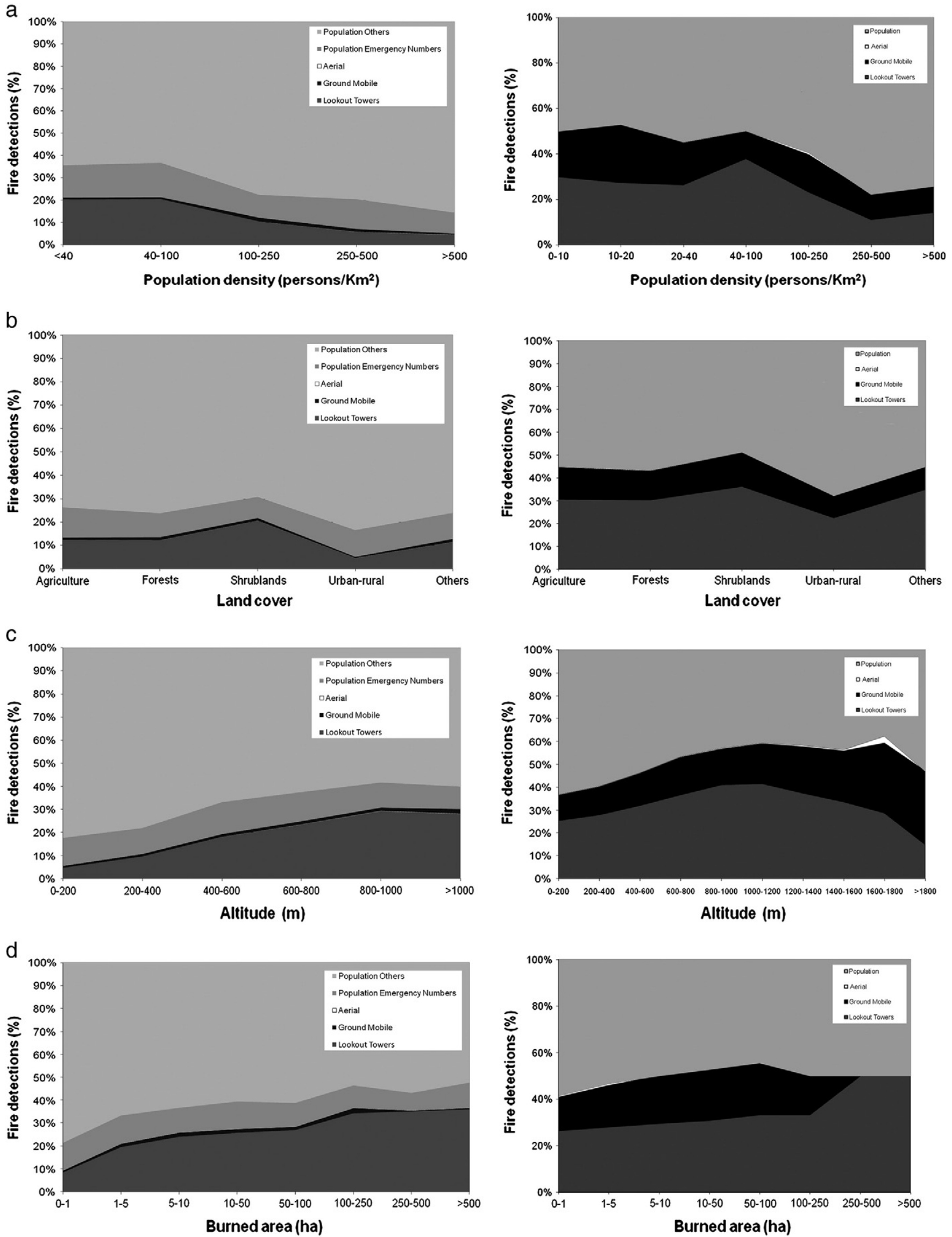

Portugal

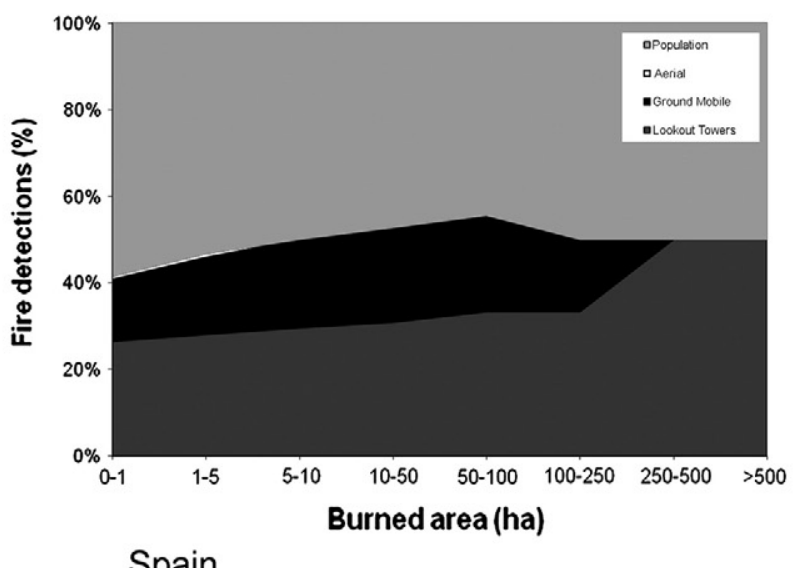

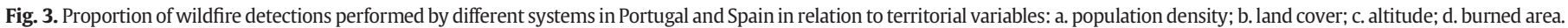


performed by each system, includes a sequence of analyses starting from visual inspections of the spatial and temporal patterns of the relative contributions of the different detection systems, followed by statistical analyses.

The preliminary analysis was performed by producing a series of maps and graphs, and by visually comparing the distribution of detection systems, their relative contribution to fire detection, and context factors (territorial variables). Since the spatial unit for fire data recording in Spain was a $10 \times 10 \mathrm{~km}$ base grid, we opted to represent the detection proportions at this level for the entire Iberian Peninsula (just for cartographic representation and visual analysis).

Statistical analyses followed the preliminary analysis. A general overview of the relation between all variables was performed using a principal component analysis (PCA) at the regional level. PCA exploratory analysis allowed the definition of the main types of relationships between detection systems' performance and territorial variables. Then, these relationships were investigated in more detail at the sub-regional level. Multiple regression analyses were used to explore the relations between the proportion of fires detected by each system (population, lookout towers, mobile brigades, and aerial means) and the potential explanatory variables. Independent variables included population density, forest proportion and shrubland proportion (Table 1 ). The results of the regression analyses are described by the estimated beta values, the value of $R$ and the corresponding significance. The use of the beta values instead of regression coefficients for comparisons is justified since they allow for a more adequate appreciation of the relative importance of the explanatory variables considered.

\section{Results and discussion}

\subsection{Assessment of fire detection systems at the national and regional levels}

The general assessment of fire detection systems performance in the Iberian Peninsula at the national level, during the period 20012007, shows that in Portugal population was responsible for $88.4 \%$ of all fire detections ( $12.2 \%$ by emergency numbers and $76.2 \%$ by other means), followed by lookout towers (10.6\% of detections), ground mobile brigades (0.9\%), and aerial systems (only $0.01 \%$ ). In Spain, population was responsible for $55.9 \%$ of all fire detections, followed by lookout towers (27.6\% of detections), ground mobile brigades (16.0\%), and aerial systems (0.6\%) (Fig. 2).

Comparing the results from Spain and Portugal, we concluded that in both countries most of the wildfires were detected by population, although in Portugal population was much more important $(88.4 \%)$ than in Spain (55.9\%). The official detection systems (i.e. lookout towers, mobile brigades and aerial means) are still very important a

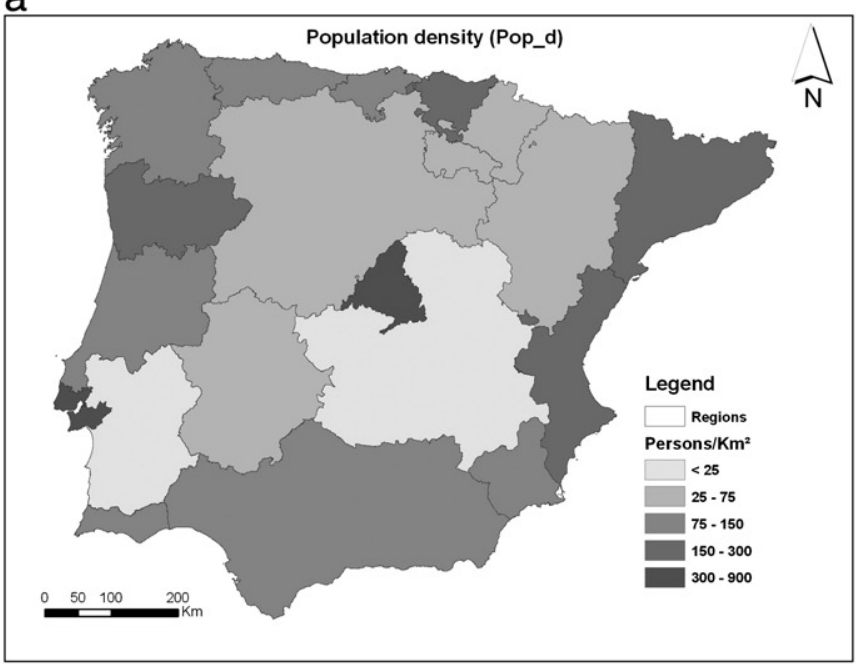

C



b

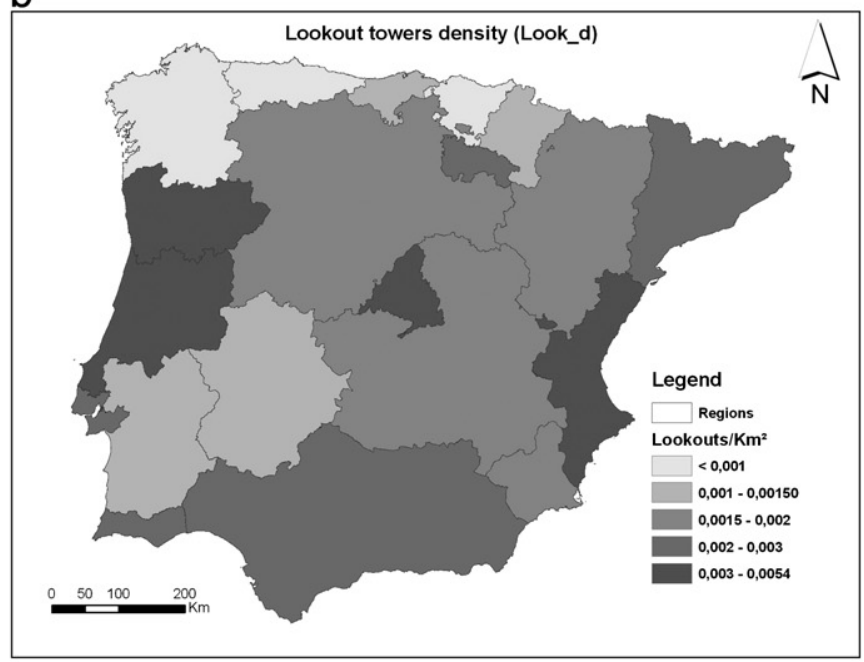

d

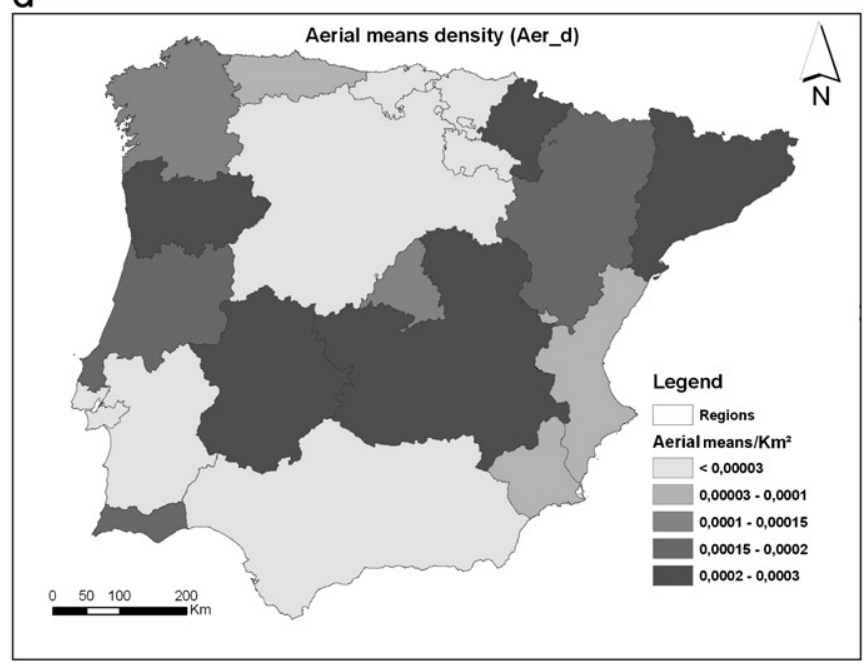

Fig. 4. Regional distribution of the different wildfire detection systems in the Iberian Peninsula: a. population; b. lookout towers; c. mobile brigades; d. aerial means. 
but play a secondary role, especially in Portugal, where they were responsible for only $11.6 \%$ of the detected wildfires ( $44.1 \%$ in Spain). The lookout towers network was the second most important source of fire detection in both countries, although in Spain it had a much higher relative importance than in Portugal $27.6 \%$ in Spain and $10.6 \%$ in Portugal). In Portugal the mobile brigades were responsible for only $0.9 \%$ of all fire detections, while in Spain this system was more important, detecting $16.0 \%$ of all fires. However, like for lookouts, the importance of mobile brigades ranges considerably among regions. In both countries the aerial means were the system responsible for fewer fire detections (only $0.01 \%$ in Portugal and $0.6 \%$ in Spain).

Lookout towers are the principal official wildfire detection system in Portugal and Spain. This system is characterised by its dependence on visibility and weather conditions (Buck, 1938; Catry et al., 2007). There are significant differences in the geographical distribution of this detection system at a regional level (Fig. 4b). The lowest density of lookout towers is found in the Basque Country (ES) and Galicia (ES), in contrast to the highest values recorded in Norte (PT), Centro (PT), Madrid (ES) and the Valencian Community (ES). On the other hand, mobile brigades are very useful as a complement to lookout towers' surveillance. This detection system is present in all regions of the Iberian Peninsula but especially in the Atlantic and Mediterranean coastal regions (Fig. 4c).

Official ground fire detection systems (lookouts and brigades) are complemented by aerial means (aircrafts), which are characterised by their large instantaneous field of vision with few non-visible areas, their ability to concentrate surveillance over strategic areas and for providing accurate information on the location of the fire. In the case of aerial means, there are no fixed patterns of spatial layout and regional differences are much larger. The concentration and
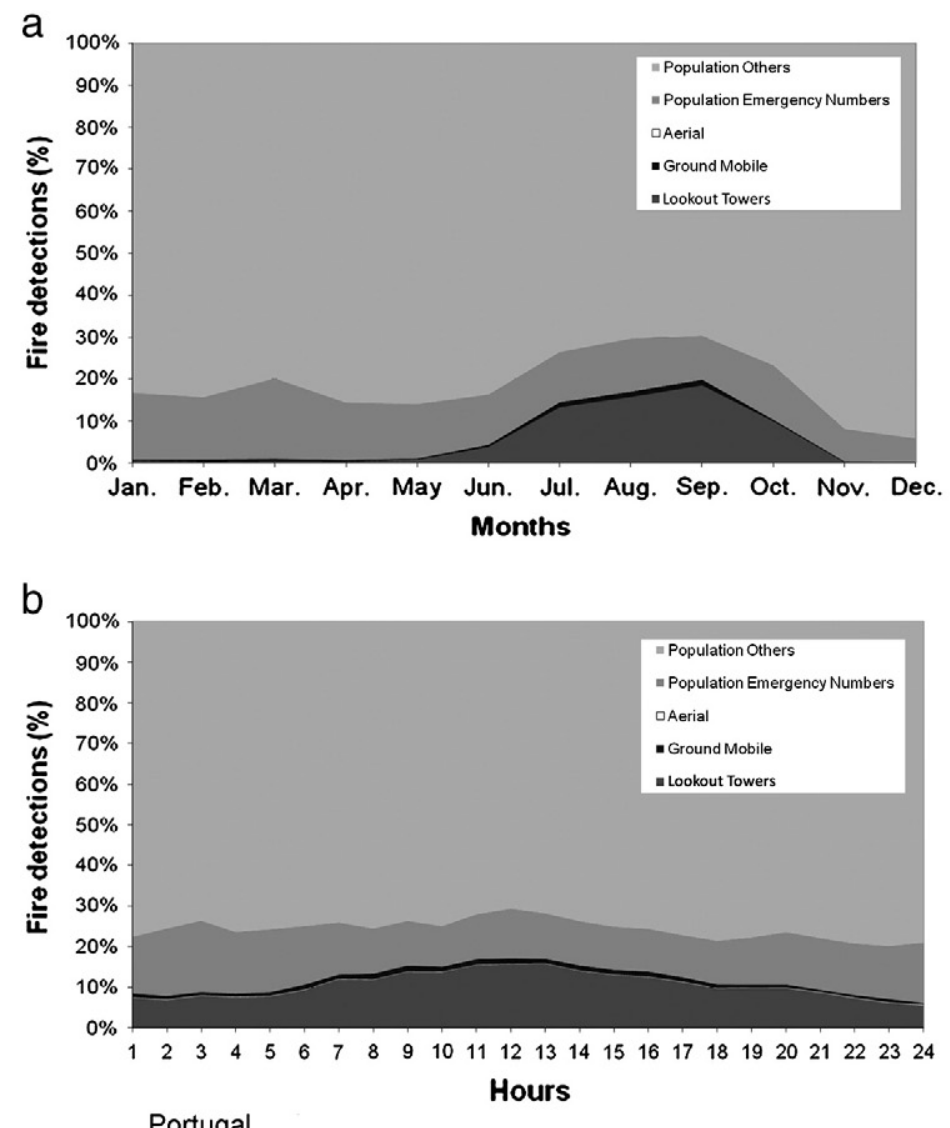

effectiveness of these systems are worth mentioning in the case of Asturias (ES), where aerial vigilance has quite a high detection rate (Fig. 7).

Finally, the population (i.e. general public) also plays a crucial role in fire detection. In fact, the population detects more than half of the fires recorded in the Iberian Peninsula.

\subsection{Spatial and temporal variables associated with fire detection systems}

Detection rates of different vigilance systems, as well as the territorial knowledge of the areas where they can effectively operate, are important information sources for fire detection planning at different spatial levels.

From the territorial variables that could be related to the different performance of the various detection systems, some are illustrated in this paper. This is the case of population density, land cover, altitude and burned area. A visual analysis of the changes in the proportion of detections performed by each system in the different classes of these variables for Portugal and Spain suggests that there are significant relations (Fig. 3). From the analysis of Fig. 3 it is apparent that, in spite of the differences between the two countries, some common trends are apparent. In both countries population density showed to be very influential, increasing its contribution to detection with increasing density, as expected. Land cover is also very significant, with higher detections by lookout towers in shrublands and less in the interface between rural and urban areas. Altitude is also related to detection. Fires at higher altitudes are less detected by population, probably as a consequence of decreasing population density with elevation. Lookout towers, typically located at higher altitudes, perform better in these situations. The proportion of area burned shows a
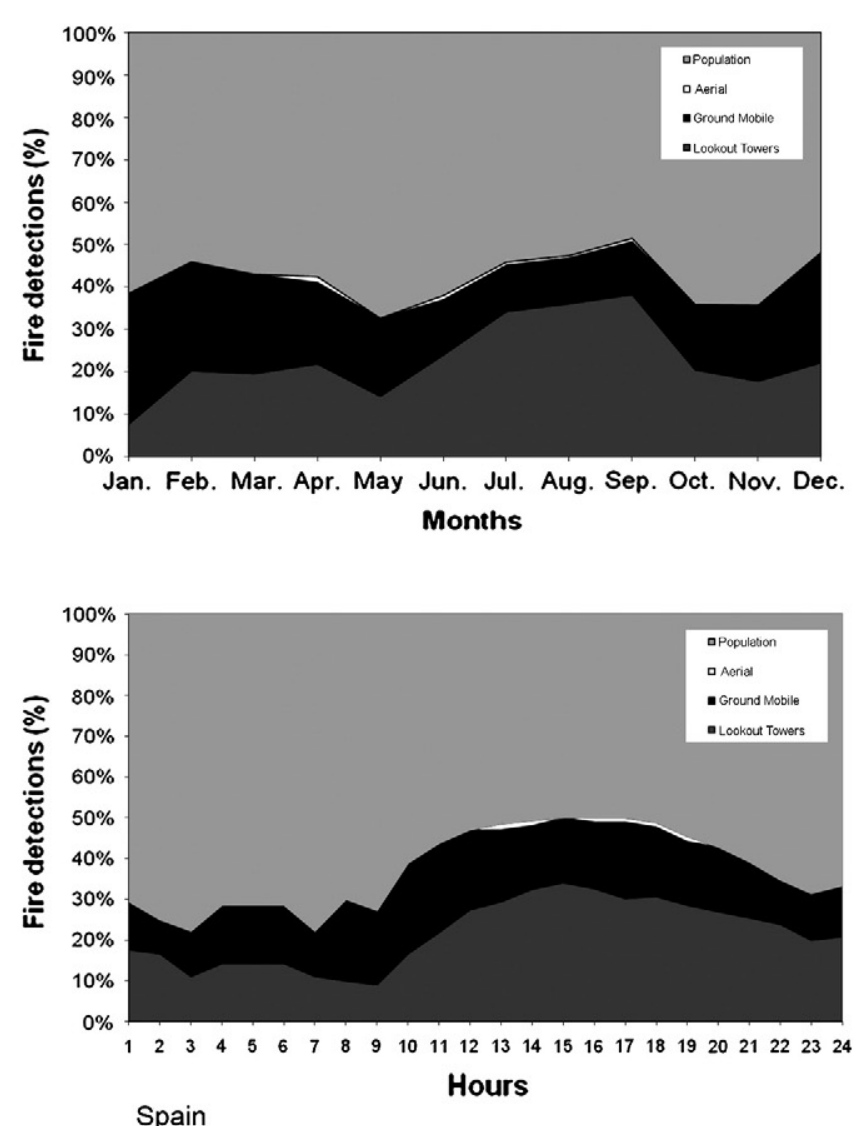


(hours). 
similar trend than elevation, as large fires tend to develop at higher altitudes.

As expected many of these territorial variables are correlated with each other and their causal relations are not necessarily straightforward. Therefore, in the development of explanatory models for detection (see next section), variables such as altitude and burned area were not used.

Also, the influence of these territorial variables in the proportion of fires detected by each system should be analysed taking into account the spatial distribution and availability of the different detection systems. In fact the density of the various systems varies significantly within the Iberian Peninsula (Fig. 4). This figure is based on data at the regional level, as many of the systems considered, and especially the mobile systems, are managed at that level, making it very difficult to perform analyses at a more detailed spatial level.

On the other hand, the proportion of fire detection made by each system is also influenced by temporal factors (Fig. 5). The detection by the various systems during the year shows important differences between the two countries. While in Portugal, the lookout towers are only active during the summer months, in Spain there are detections by lookout towers and mobile brigades throughout the year explaining, at least partly, the higher overall proportions of fires detected by these systems in Spain. The variation during the day shows a better performance for lookout towers in the daytime than at night, as mentioned by several authors (Catry et al., 2009; Chandler et al., 1983), with a maximum performance at the warmer period of the day. This is possibly related with a stronger convection in that period that allows for a fast smoke rising and a fast detection by lookouts typically located at higher elevations, or because of higher observer alertness at the time of higher fire danger.

\subsection{Statistical analysis: regression models based on territorial variables}

The spatial distribution of land cover and fire regime variables is shown in Fig. 6 at the sub-regional level. The spatial distribution of the proportion of fires detected by each system in the Iberian Peninsula can be observed in Fig. 7.

There are obvious differences between Portugal and Spain in what concerns the relative importance of fire detections made by population, mobile brigades and aerial means. The main differences can be explained by the communication systems in Portugal, where mobile brigades and aerial means often share the same communication channels as population, while in Spain these detection systems always use independent communication channels.

Comparing Fig. 7 with the geographical distribution of the detection systems at the regional level (Fig. 4), some relationships are

b
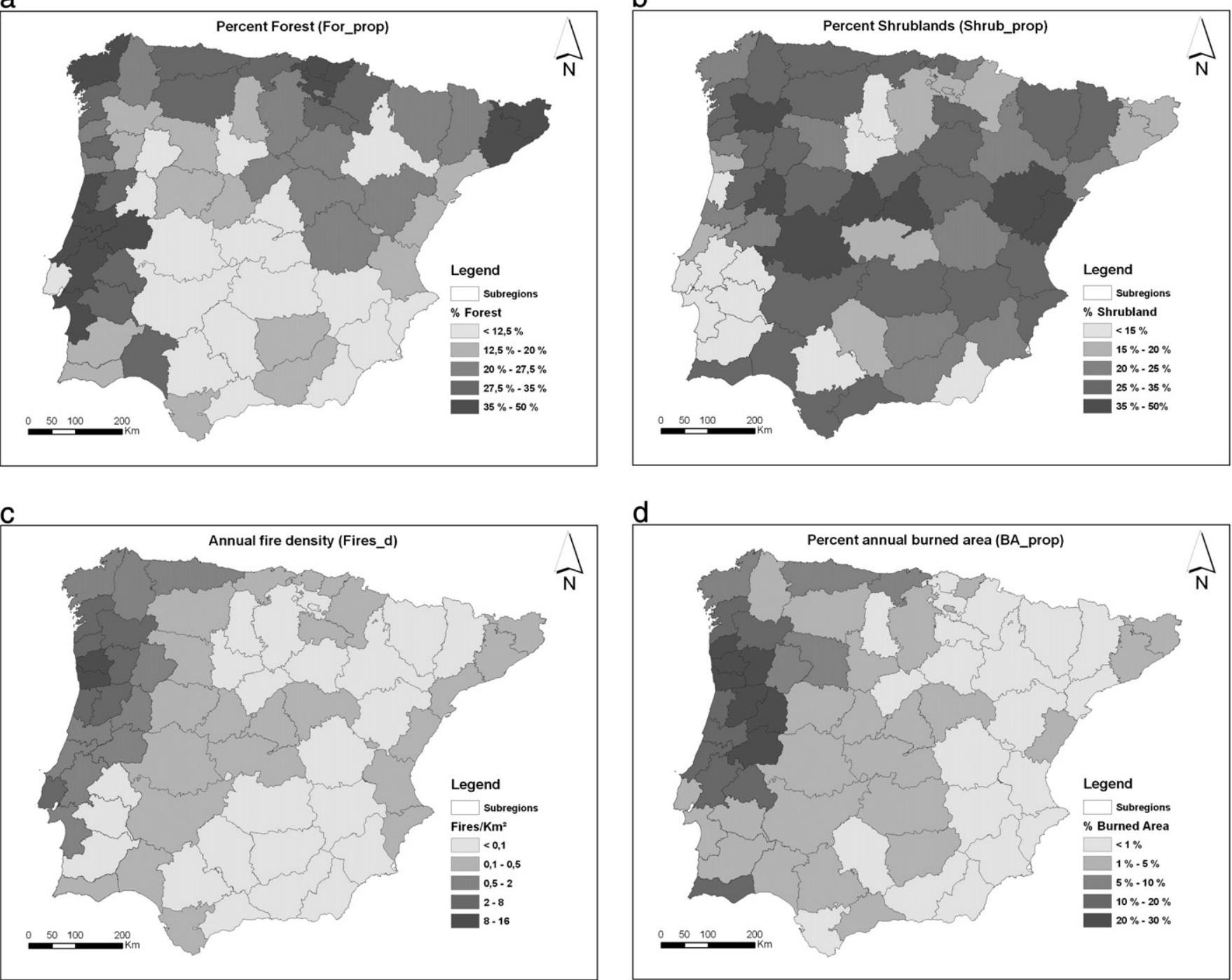

d

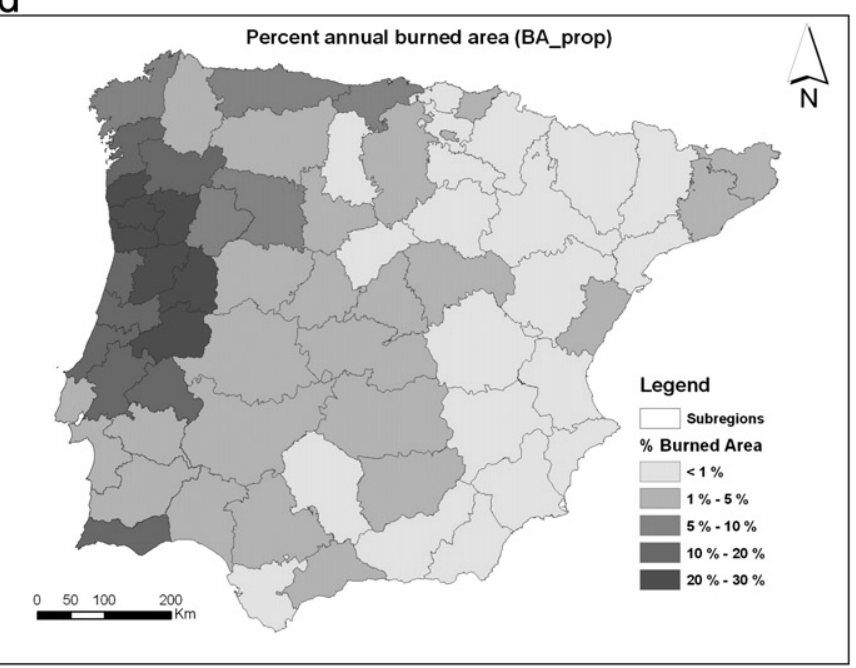

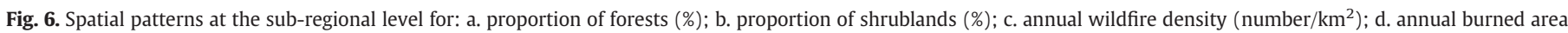
proportion (\%). 
a

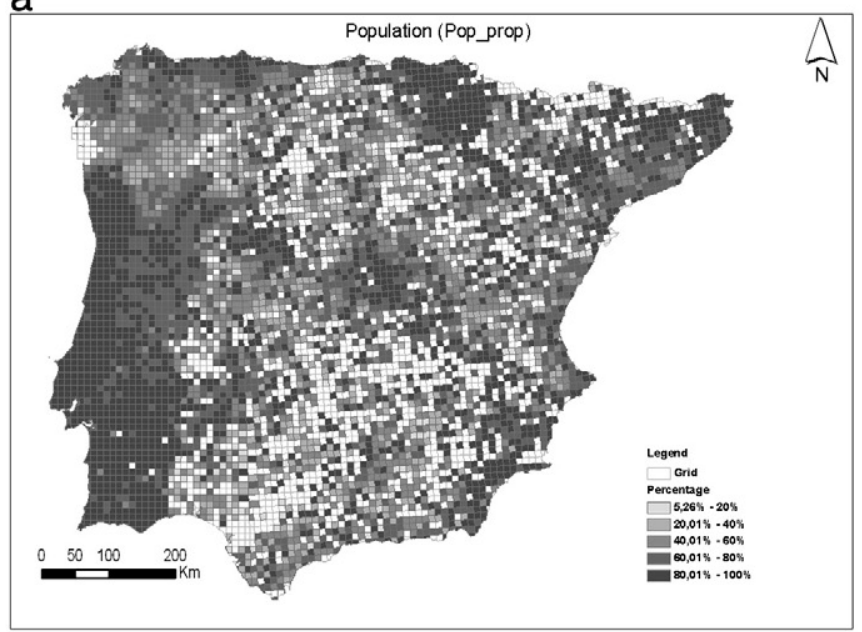

C

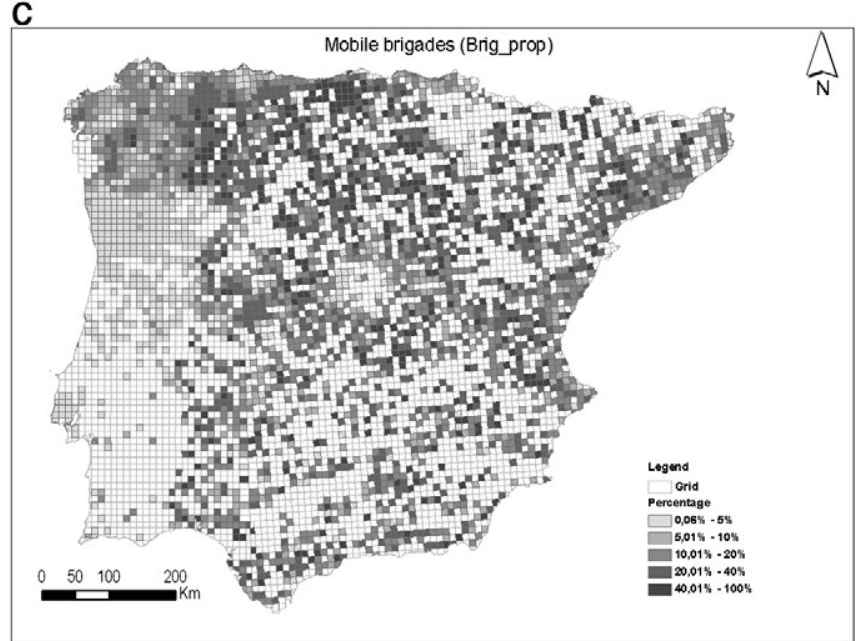

b

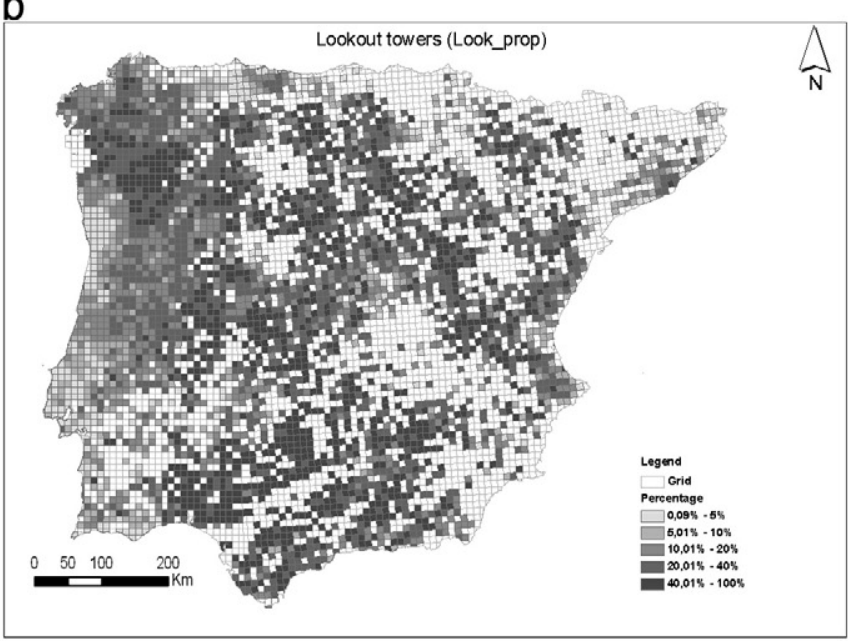

d

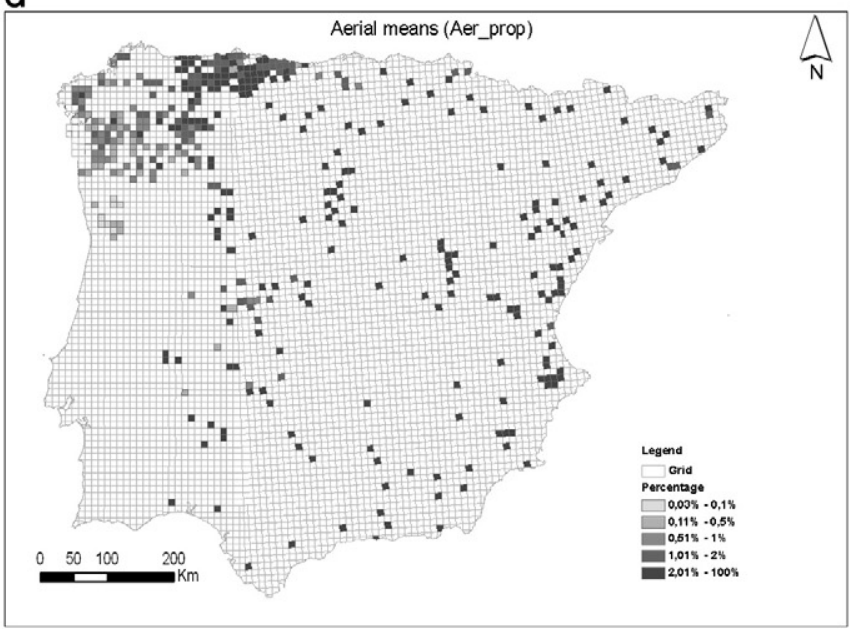

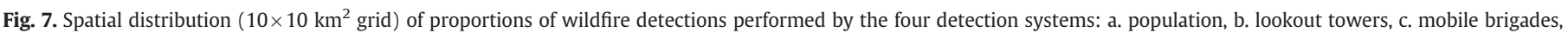
d. aerial means.

apparent within each country, especially in the correspondence of the higher importance of detection by population with areas of high population density.

The exploratory analysis of the relationships between the different types of variables was done for the Iberian Peninsula using a principal component analysis (PCA) technique. As data for the detection systems are only available for the whole Peninsula at the regional level, this was the level used in this analysis.

The first two components explained $32.6 \%$ and $17.9 \%$ of the total variance respectively and the plot of variable loadings is represented in the component plot of Fig. 8 .

The results show a first axis associated with population where the proportion of fires detected by population is shown to be related to population density, as expected. These results are in agreement with Chandler et al. (1983) who indicate that in those areas having a high human population, a good proportion of fires are detected by the public. The plot also indicates that the first axis is related positively to the density of mobile brigades, to fire density, and to the proportion of burned area. In the other side of the axis, in regions of lower population density, the proportion of fires detected by mobile brigades and aerial means increase.

A second axis is associated with land cover. It is apparent that higher proportions of fires detected by lookout towers are associated with lower proportions of forests and higher proportions of shrublands.
It is apparent from this analysis that the increase of density of brigades and aerial means results in the increase of fires detected by population. A more detailed analysis could be performed at the sub-regional level but data on detection systems is not available at that level. Thus we developed explanatory models based only on three territorial variables available at the sub-regional level (population density, proportion of land with forest and shrub) (Table 2).

\section{Conclusions}

This study is the first attempt to analyse the general patterns and performance of wildfire detection systems in the entire Iberian Peninsula, and to correlate it with territorial variables.

Official records of fire detection in Spain and Portugal show important differences partly due to different fire management systems, different priorities given in distributing detection resources and different operational and communication options. Our results show a much higher proportion of fires detected by population in Portugal, and much lower proportion of fires detected by mobile brigades and, to a lesser extent, by aerial means. This may be due to the fact that in Portugal the communication channel of fire discovery by brigades and aerial means is often the same as for the general population and therefore these discoveries are considered as detections by population. 


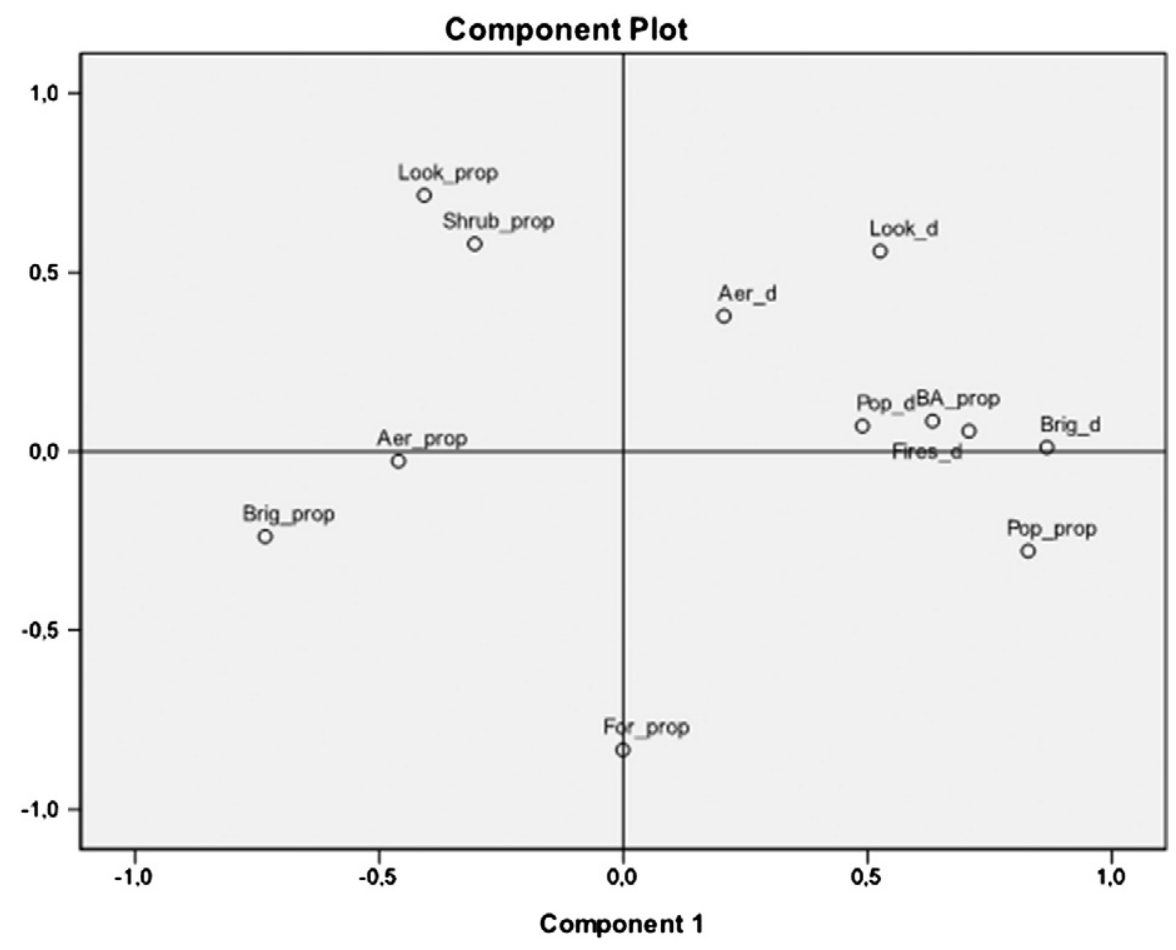

Fig. 8. Plot of variables resulting from the principal component analysis performed at the regional level.

At the regional level, we concluded that the proportion of detections made by each system is not always related to the density of that system. In the case of population the relationship between detection rates and population density is very strong. On the contrary, for lookout towers, mobile brigades and aerial means this correlation is not evident, while territorial variables show important influence. Territorial variables, such as land cover and population density, were indeed found to be explanatory factors of the performance of the different detection systems.

Models developed at the sub-regional level indicate that a higher proportion of forestlands are associated with lower detection levels by lookout towers (and higher detection by population) whereas a higher proportion of shrublands indicate lower detection rate by population with corresponding higher proportion of detection by other systems (lookout towers, mobile brigades and aerial means). The presented models confirm that population density is a very important variable, being positively related to the proportion of fires detected by population, and negatively related to the other systems.

It can be concluded that the comparative success of the different fire detection systems is related to different context factors described by territorial variables. The analysis of the territorial context allows for the use of the more adapted systems and for searching the optimal complementarities.

\section{Table 2}

Beta values of the multiple linear regression analysis with the proportions of fires detected by each system as dependent variables and territorial variables as independent variables (sub-regional level).

\begin{tabular}{clrcll}
\hline \multirow{5}{c}{ Dependent variables } \\
\cline { 3 - 6 } & & Pop_prop & Look_prop & Brig_prop & Aer_prop \\
\hline Independent & Pop_d & 0.291 & -0.260 & -0.164 & -0.143 \\
variables & For_prop & 0.335 & -0.428 & -0.033 & -0.097 \\
& Shrub_prop & -0.220 & 0.170 & 0.157 & 0.115 \\
& R value & 0.569 & 0.598 & 0.249 & 0.237 \\
& significance & $<0.001$ & $<0.001$ & n.s. & n.s. \\
\hline
\end{tabular}

Codes: Pop_d, population density; For_prop, proportion of forests; Shrub_prop, proportion of shrublands.
The use of this information can be important to optimize detection costs and to inform policy decisions at the country and regional level for the allocation of resources for wildfire detection. This approach could also be used by decision-makers for similar objectives in other countries or regions.

\section{Acknowledgements}

We hereby acknowledge the European Commission for the support through the project Fire Paradox (FP6-018505) and the many participants of the project who contributed to the discussion on these matters. We also acknowledge the forest authorities of Portugal and Spain for their contributions with data and related information that made this paper possible.

\section{References}

Arrue, B.C., Martínez-de Dios, J.R., Ollero, A. 2006. Evaluation of fire danger for initial attack from fire detection images. Forest Ecology and Management. http://dx.doi.org/ 10.1016/j.foreco.2006.08.257.

Buck, C.C., 1938. Factors influencing the discovery of forest fires by lookout observers. Journal of Agricultural Research 56 (4), 259-268 (Washington, DC).

Catry, F., Rego, F., Santos, T., Almeida, J., Relvas, P., 2007. Forest fires prevention in Portugal - using GIS to help improving early fire detection effectiveness. Wildfire2007: 4th International Wildland Fire Conference, CD Rom. Seville, Spain, 13-17 May 2007.

Catry, F., Rego, F., Bacao, F., Moreira, F., 2009. Modeling and mapping wildfire ignition risk in Portugal. International Journal of Wildland Fire 18, 921-931.

Catry, F.X., Rego, F.C., Silva, J.S., Moreira, F., Camia, A., Ricotta, C., Conedera, M., 2010 Fire starts and human activities. In: Silva, J.S., Rego, F., Fernandes, P., Rigolot, E. (Eds.), Towards Integrated Fire Management - Outcomes of the European Project Fire Paradox. European Forest Institute Research Report, 23. EFI, Joensuu, pp. 9-22.

Chandler, C., Cheney, P., Thomas, P., Trabaud, L., Williams, D., 1983. Detection. Fire in Forestry - Volume II: Forest Fire Management and Organization. John Wiley and Sons, Inc., New York, pp. 69-73.

Colaço, M.C., Rego, Montiel, C., Solana, J., Herrero, G., Alexandrian, D., Ubysz, B. Szczygiel, R., Piwnicki, J., Sesbou, A., 2008. Review of the existing fire detection systems in Europe and North Africa. III International Symposium on Fire Economics, Planning and Policy Common Problems and Approaches, Carolina, Puerto Rico, April 29-May 2, 2008.

Colaço, M.C., Rego, F., Correia, A., Montiel, C., Alexandrian, D., Lagarde, I., Ubysz, B., Szczygiel, R., Piwnicki, J., Sesbou, A., 2009. Wildfire detection in Europe, Morocco and Tunisia. Advances in Environmental Research, vol. 3. Nova Science Publishers. 
EEA, 2000. CORINE Land Cover 2000. European Environment Agency. (Available at: http://www.eea.europa.eu/publications/COR0-landcover).

European Commission, Joint Research Centre, 2009. Forest fires in Europe 2008. JRC Scientific and Technical Reports, № 9. Office for Official Publications of the European Communities, Luxembourg.

Ko, B.C., Cheong, K.-H., Nam, J.-Y., 2009. Fire detection based on vision sensor and support vector machines. Fire Safety Journal 44, 322-329.

Montiel, C., Solana, J., Herrero, G., 2009. Sistemas de detección de incendios forestales en España. Revista Montes 9, 89-95.

Moreira, F., Catry, F.X., Rego, F., Bacao, F., 2010. Size-dependent pattern of wildfire ignitions in Portugal: when do ignitions turn into big fires? Landscape Ecology 25, $1405-1417$.

Oliva, P., Jurado, S., Martínez, J., y Chuvieco, E., 2008. Validación y comparación de los productos MODIS y AATSR para la detección d focos activos en la España Peninsular y Baleares en el año 2003, UNED. Espacio, tiempo y forma, Serie VI, Geografía, nº 1 , pp. 141-150.
Pérez, R., Ventosa, C., Villalba, D., 2007. Optimización de sistemas de detección. Wildfire2007: 4th International Wildland Fire Conference, Seville, Spain, 13-17 May 2007.

Rego, F., Catry, F., 2006. Modelling the effects of distance on the probability of fire detection from lookouts. International Journal of Wildland Fire 2006 (15), 197-202.

Romero, A.M., Bardají, M., Clavero, M.A., 2007. Estudio de los puestos fijos de vigilancia contra incendios forestales en la Comunidad Autónoma de Aragón. Aplicación a la zona de Sobrepuerto (Huesca). Wildfire2007: 4th International Wildland Fire Conference, Seville, Spain, 13-17 May 2007.

Ruiz, E.M., 2000. Detección. In: Vélez, R. (coord.) (Ed.), La defensa contra incendios forestales. Fundamentos y experiencias. McGraw-Hill, Madrid, pp. 17.1-17.15.

Seric, L., Stipanicev, D., Stula, M., 2009. Observer network and forest fire detection. Information Fusion. http://dx.doi.org/10.1016/j.inffus.2009.12.003.

Zervas, E., Mpimpoudis, A., Anagnostopoulos, C., Sekkas, O., Hadjiefthymiades, S., 2009. Multisensor data fusion for fire detection. Information Fusion. http://dx.doi.org/ 10.1016/j.inffus.2009.12.006. 